\title{
Correspondence
}

\section{Lymphocyte transformation to bacterial antigens in ankylosing spondylitis}

SIR, Several diseases have now been shown to be associated with the histocompatibility antigen HLA B27, including ankylosing spondylitis, Reiter's disease, acute anterior uveitis, and peripheral arthritis. Over $90 \%$ of patients with spondylitis carry B27, but only $10-25 \%$ of those carrying that antigen develop spondylitis or other B27related disease.

It has therefore been suggested that these diseases might reflect an abnormal immune response to a microorganism in the environment. It is known that there is an increased frequency of HLA B27 in patients. who develop a reactive, nonspecific, peripheral arthritis or spondylitis following an intestinal infection with Yersinia enterocolitica, shigella, or salmonella following urethritis associated with Chlamydia trachomatis or following a brucella infection. The mechanism of this inherited susceptibly is not known. If the responsible organisms were known to carry 1 common antigen, then the defective response could be due to the antigen cross-reacting with B27 itself, and therefore not recognised as foreign. Alternatively, B27 could merely be acting as a marker for an unusual response to this common antigen.

Unfortunately, strains of shigella and salmonella from patients with reactive arthritis and B27 are not available to test this hypothesis and there are no published data establishing an antigenic cross-reaction between chlamydia and yersinia. Another possibility is that there might be an allergic response to enteric or urethral antigens not present in the microbes but nevertheless exposed in response to infection with the organisms.

We have previously reported preliminary evidence that lymphocyte transformation to a crude, mixed Yersinia enterocolitica and pseudotuberculosis antigen is reduced in individuals with B27 (Nikbin et al., 1975). In 1976 we repeated and extended these investigations to see if specific yersinia antigens could be implicated in ankylosing spondylitis, recognising that Yersinia enterocolitica grows over a wide temperature range and is known to have different somatic and flagellar antigens at $15^{\circ} \mathrm{C}$ and $35^{\circ} \mathrm{C}$. In addition 3 other enterobacteria were tested: Enterobacter aerogenes (an organism said to cross-react with B27-positive lymphocytes), Salmonella typhi, and a haemolytic-necrotoxin-producing Escherichia coli strain, serotype 02 . The $E$. coli strain was included because haemolysis and necrotoxin production are found with increased frequency in patients with a relapse of ulcerative colitis, and ulcerative colitis is associated with spondylitis, particularly in patients with B27. Patients and controls were tested at the same time, in batches.
The 22 patients had definite ankylosing spondylitis with B27. They were all males under 50 years, and their disease was sufficiently inactive that they were either taking no drugs or were able to take no drugs for 3 weeks before investigation. The 27 normal controls were also males under 50 years, age matched by decades. Fewer patients were studied with the enterobacter antigen. Subsequently, in 1978, we have had the opportunity to study 2 patients who are respectively the eleventh and twelfth patients with Yersinia enterocolitica infection in England and Wales that have been reported to the Communicable Disease Surveillance Centre. Both patients had documented Yersinia enterocolitica serotype 3 infections. One, a male aged 20 (genotypically homozygous HLA B27), had acute reactive arthritis with onset 4 months before testing and was receiving indomethacin when tested. The second, a female aged 25 (without HLA B27), had enteric symptoms some 2 months before testing but no arthritis.

Lymphocyte transformation to 7 bacterial antigens was studied. A one-way mixed lymphocyte reaction (MLR) using a mitomycin-C treated pool of 5 unrelated donors was also performed. Strains of serotype 3 and serotype 9 of Yersinia enterocolitica from patients with reactive arthritis (kindly provided by $\mathrm{Dr} \mathrm{K}$. Aho of Helsinki) were grown at $15^{\circ} \mathrm{C}$ and $35^{\circ} \mathrm{C}$ on nutrient agar and harvested into phosphate buffered saline pH 7.2. Freezeexpressed antigenic extracts of these strains were kindly prepared within 4 hours of harvesting by Dr W. D. Brighton at the National Institute for Biological Standards. Thus 4 different preparations of Yersinia enterocolitica were used as individual immunogens. Expressed extracts of a strain of Enterobacter aerogenes (kindly donated by $\mathrm{Dr}$ A. Ebringer), and a strain of $E$. coli $\mathrm{O}_{2}$ $\mathrm{HL}+\mathrm{Nec}+$ grown on solid media (donated by Professor E. M. Cooke) were similarly prepared. All extracts were lyophilised as aliquots for subsequent use.

Lymphocyte transformation tests were carried out as previously described (Yamamura et al., 1976). In summary, lymphocytes were isolated from heparinised blood on Lymphoprep (Nyegaard, Oslo) and then incubated in flat-bottomed microtitre plates; each well contained $10^{5}$ cells in TC 199 with $25 \%$ autologous plasma and antigen at an optimal concentration previously determined on 3 normal controls. In the 2 known yersinia patients tests were also carried out in AB plasma. The plates were incubated for five days at $37^{\circ} \mathrm{C}$ in $5 \% \mathrm{CO}_{2}$; then $0.5 \mu \mathrm{Ci}$ tritiated thymidine was added, and the cultures harvested after a further 18 hours' incubation. Samples were counted with a scintillation counter. All tests were performed in triplicate. Results with the bacterial antigens in 1976 are expressed in Table 1 and in 1978 in Table 2.

As can be seen in Table 1 the range of response to all 7 bacterial antigens is extremely large in both patient and control groups. A Mann-Whitney rank test was used to 
Table 1 Lymphocyte transformation (c.p.m.)

\begin{tabular}{|c|c|c|c|c|}
\hline \multirow[b]{2}{*}{ Antigen } & \multicolumn{2}{|c|}{ Controls } & \multicolumn{2}{|c|}{ Patients } \\
\hline & Mean & Range & Mean & Range \\
\hline & \multicolumn{2}{|c|}{$n=27$} & \multicolumn{2}{|c|}{$n=22$} \\
\hline $\begin{array}{l}\text { Background } \\
\text { Y. enterocolitica }\end{array}$ & 1159 & $47-5158$ & 772 & 46-2292 \\
\hline $\begin{array}{l}9\left(15^{\circ} \mathrm{C}\right) \\
\text { Y. enterocolitica }\end{array}$ & 4419 & $316-18736$ & 2665 & $165-6610$ \\
\hline $\begin{array}{l}9\left(35^{\circ} \mathrm{C}\right) \\
\text { Y. enterocolitica }\end{array}$ & 6692 & $810-36957$ & 4285 & $392-24431$ \\
\hline $\begin{array}{l}3\left(15^{\circ} \mathrm{C}\right) \\
\text { Y. enterocolitica }\end{array}$ & 6440 & $725-30431$ & 4633 & $405-26783$ \\
\hline $3\left(35^{\circ} \mathrm{C}\right)$ & 3653 & $40-16153$ & 2389 & $66-14017$ \\
\hline S. typhi & 3284 & $374-8104$ & 2502 & $174-6119$ \\
\hline E. coli & 3557 & $375-15860$ & 2578 & $119-7514$ \\
\hline \multirow[t]{2}{*}{ MLR } & 46941 & 13839-79587 & 42179 & $17405-68812$ \\
\hline & \multicolumn{2}{|c|}{$(n=16)$} & \multicolumn{2}{|c|}{$(n=13)$} \\
\hline E. aerogenes & 534 & $1078-14761$ & 4676 & $1591-12176$ \\
\hline
\end{tabular}

Table 2 Lymphocyte transformation in patients with yersinia infection (c.p.m. \pm standard deviation)

\begin{tabular}{|c|c|c|c|c|}
\hline \multirow[b]{2}{*}{ Serum } & \multicolumn{2}{|c|}{$\begin{array}{l}\text { Patient with } \\
\text { yersinia arthritis }\end{array}$} & \multicolumn{2}{|c|}{$\begin{array}{l}\text { Patient without } \\
\text { yersinia arthritis }\end{array}$} \\
\hline & Autologous & $A B$ & Autologous & $A B$ \\
\hline \multirow{5}{*}{$\begin{array}{l}\text { Control } \\
\text { Y. entero- } \\
\text { colitica } 3 \\
\left(15^{\circ}\right) \\
\text { Y. entero- } \\
\text { colitica } 3 \\
\left(35^{\circ}\right) \\
\text { Y. entero- } \\
\text { colitica } 9 \\
\left(15^{\circ} \mathrm{C}\right) \\
\text { Y. entero- } \\
\text { colitica } 9 \\
\left(35^{\circ} \mathrm{C}\right)\end{array}$} & $486 \pm 84$ & $1002 \pm 648$ & $1477 \pm 117$ & $1630 \pm 292$ \\
\hline & $816 \pm 279$ & $5440 \pm 759$ & $1882 \pm 410$ & $6182 \pm 1043$ \\
\hline & $598 \pm 104$ & $4663 \pm 1393$ & $1807 \pm 111$ & $6215 \pm 1636$ \\
\hline & $1211 \pm 567$ & $4373 \pm 1174$ & $2590 \pm 1227$ & $7565 \pm 902$ \\
\hline & $613 \pm 89$ & $1404 \pm 398$ & $1848 \pm 217$ & $2594 \pm 599$ \\
\hline
\end{tabular}

All antigens at final concentration of $50 \mathrm{mg} / \mu$ (optimum), $25 \%$ serum, $10^{5}$ cells/well. Final volume $0.2 \mathrm{ml}$.

compare patients and control groups, and no significant difference was demonstrated for any of the bacterial antigens tested. Since the MLR is normally distributed, the patient and control groups were compared by Student's $t$ test and no significant difference was found on this occasion. This conflicts with our previous finding of a reduced MLR in patients with ankylosing spondylitis and their relations with HLA B27 (Nikbin et al., 1975; Yamamura et al., 1976). From Table 2 it can be seen that there is no apparent difference in response between the 2 patients with known yersinia infection. Although no controls were included in 1978, the responses do not differ significantly from either patients with spondylitis or controls tested with the same lyophilised antigen in 1976.

Although there are many possibilities, we cannot adequately explain why the MLR was diminished in patients with ankylosing spondylitis on 2 previous studies but not in the third, despite selecting similar patients and using the same laboratory technique. Even in retrospect we have no criticisms of our 2 earlier investigations. We would be interested to learn whether other workers have $\overrightarrow{\vec{A}}$ experienced apparent fluctuation in the MLR in spondy-? litic patients.

There are also several possible reasons why no dif- $\frac{}{\bar{T}}$ ferences were detected in the responses to bacterial $\frac{\bar{\rho}}{7}$ antigens when comparing spondylitic patients with $\stackrel{\mathbb{Q}}{\mathscr{Q}}$ controls. Firstly, we may be looking at the wrong bacteria. Yersinia enterocolitica was chosen because it can cause a reactive peripheral arthritis in patients with $\vec{\circ}$ B27. There is no evidence that this organism is involved in ankylosing spondylitis. Secondly, we may not be using $\vec{\omega}$ appropriate antigens. Our original work in 1974 used a single crude mixture of formalin killed Yersinia entero- $\bar{\alpha}$ colitica serotypes 3 and 9 grown at $15^{\circ} \mathrm{C}$ and $35^{\circ} \mathrm{C}$ mixed $\omega_{\infty}$ with Yersinia pseudotuberculosis serotype 1. The latter is an organism considerably more common than the former in the UK but not implicated in arthritis associated with 9 B27. This work used differently prepared homogenous 0 antigens. We do not know if a single bacterial antigen is involved in B27-associated disease, and therefore we $\vec{D}$ cannot test for its expression in any of the preparations we have used. Thirdly, lymphocyte transformation may be the wrong test to use to try and detect subtle differ- $\vec{\theta}$ ences in a response to antigen. Its sensitivity is not great, $\circlearrowright$ and specificity is limited by the large number of antigens present in a crude extract. The failure to demonstrate any difference in reactivity between 2 patients with recent yersinia infection (1 with and 1 without arthritis and $\bar{D}$ B27) suggests that the latter 2 reasons may be implicated in this study.

The lack of a significant difference between patients with $\Rightarrow$ spondylitis and controls in response to these bacterial antigens does not mean that an infection or other environmental agent is not involved in ankylosing spondylitis either directly or indirectly. It merely means that more sophisticated and sensitive methods must be used to search for it.

A. C. MAWLE and J. R. HobBs Department of Chemical Pathology, Westminster Hospital, London.

R. E. WARREN Department of Bacteriology, Addenbrooke's Hospital, Cambridge. $\%$

D. A. BREWERTON N Department of Rheumatology, $\mathrm{\omega}_{\mathrm{W}}$ Westminster Hospital, London. O्

References Malka, S., McLeod, L., Slater, L. Warren, R. E. and Hobbs, J. R. (1975). Lymphocyte antigens in ankylosing spondylitis. Annals of the Rheumatic Diseases, 34, Supple- $\bigcirc$ ment, 49.

Yamamura, M., Nikbin, B., Hobbs, J. R. (1976). Standardisation of the mixed lymphocyte reaction. Journal of Immunological Methods, 10, 367-378. 